\title{
$\mathrm{IPA}$ 를 적용한 방장산 자연휴양림의 활성화 방안
}

\author{
허예나 ${ }^{1} \cdot$ 양천은 $^{1} \cdot$ 김강산 $^{1} \cdot$ 김민희 ${ }^{2} \cdot$ 안기완 $^{3 * *}$
}

${ }^{1}$ 전남대학교 대학원 임학과, ${ }^{2}$ 전남대학교 농업과학기술연구소, ${ }^{3}$ 전남대학교 산림자원학부

\section{Activation Plan of Bangjang Mt. National Recreational Forest based on Importance-Performance Analysis}

\author{
YeNa $\mathrm{Heo}^{1}$, CheonEun Yang ${ }^{1}$, KangSan $\mathrm{Kim}^{1}$, MinHee $\mathrm{Kim}^{2}$ and KiWan $\mathrm{An}^{3, *}$ \\ ${ }^{1}$ Department of Forestry, Graduate School, Chonnam National University \\ ${ }^{2}$ Institute of Agricultural Science \& Technology, Chonnam National University \\ ${ }^{3}$ Division of Forest Resources, Chonnam National University \\ *Corresponding author: kiwan@jnu.ac.kr
}

\begin{abstract}
The study was conducted to provide activation plan through the user's behavior and importance-satisfaction analysis of visitors to Bangjang Mt. National Recreational Forest. The survey was conducted for the purpose of preliminary investigation from June 15 to June 24, 2017, and about 40 cases were surveyed and were used for analysis except for non-response surveys. As a result of the analysis, many visitors who visited for rest, and the visitors who visited for the first time showed the highest rate. Also, most of the visitors visited with their families, and the percentage of visitors staying for one night was high. The result of IPA(Importance-Performance Analysis) showed that 10 attributes are included such as facility location and management, reservation system in the "Keep up the Good work" part; 3 attributes are included such as toilet location and management in the "concentrate Here" part; and 11 attributes are included such as number of toilet, number of accommodation facility in the "low priority" part.
\end{abstract}

Additional key words: Bangjang Mt. National Recreational Forest, Visitors behavior, IPA (Importance-Performance Analysis)

서 론

자연휴양림은 산림자원의 지속가능한 경영을 도 모하면서 숙박시설, 편의시설 등 기본적인 휴양시 설을 설치하여 국민의 보건휴양, 정서함양, 산림교
육 등을 위한 야외휴양공간을 제공함과 동시에 산 림소유자의 소득향상에 이바지하기 위한 산림이다 (http://www.forest.go.kr).

자연휴양림은 1980 년대 후반부터 대관령 자연 휴양림을 시작으로 1990년도에는 산림법을 정비하 
고, 2005년에는 산림문화휴양에 관한 법률을 제정 하는 등 법적, 제도적 장치를 마련하여 본격적인 추진체제를 갖추었다. 최근, 국민 소득수준 증가와 노령인구의 증가로 인하여 삶의 질, 복지, 만족도 등 건강한 삶, 행복한 삶에 대한 대국민적 관심이 높아졌고, 복잡한 도시생활과 끊임없는 스트레스 로 인한 우울증, 불안장애 등의 정신건강을 위협 하는 요소들의 증가로 인한 해소법으로 숲치유, 자연휴양림 등 산림휴양에 대한 관심이 증가하고 있는 추세이다(윤혜진, 2009). 현재, 국립 자연휴 양림은 40 개소로 국민에게 건전한 휴식 공간 제 공, 자연학습교육장 활용, 다목적 산림경영, 산촌 주민 소득증대 기여의 설립목적을 가지고 있으며, 나아가 현대인들의 스트레스 해소의 자연공간으로 활용되고 있다. 자연휴양림 운영기관인 국립자연 휴양림관리소에서는 국립 자연휴양림에 비즈니스 모델을 도입하는 등 나름대로의 자구책 마련에 총 력을 기울이고 있으나, 예산운용의 구조적 문제, 수지 불균형의 문제, 전문 인력 확보의 문제 등 해결해야 할 다양한 현안과제들을 안고 있다. 박 종찬(2009)은 국립 자연휴양림이 성장을 지속하고 국민에게 건전한 휴식공간, 자연공간 등을 제공하 기 위해서는 다양한 측면에서의 노력이 필요하고, 무엇보다 국립 자연휴양림의 기초자료 확보가 선행
되어야 할 것이며, 이를 바탕으로 활성화 요인을 도 출, 객관적이고 체계적인 연구와 정책수립이 필요 함을 제안하기도 하였다.

국립 방장산 자연휴양림(방장산 자연휴양림이라 칭한다)은 전라남도 장성군 북이면 방장로 353(그 림 1)에 위치하며(http://www.huyang.go.kr), 2000년 에 개장하였고 고로쇠나무, 신갈나무, 굴참나무 등 674 ha에 참나무류가 주 임분을 이루고 있으며, 임 분 내에는 다양한 초본류가 자생하고 있어 산림교 육에 적합한 자연휴양림이다. 자연친화적인 통나무 집 및 황토로 지어진 숙박시설은 1일 149명을 수 용할 수 있으며, 권역 내에는 최저 300명에서 600 명의 수용력을 가지고 있다. 이와 더불어 솦속공예 마을, 에코어드벤처, 세미나실 등 시설이 마련되어 있어 다양한 연령층의 가족이 함께 즐길 수 있다. 방장산 자연휴양림에 가장 인기가 높은 시설물인 숲속공예마을에서는 휴양림을 찾은 가족단위의 고 객에게 나무를 이용하여 개인이 필요한 나무목걸 이, 우드버닝 문패, 편백비누 만들기, 편백 물비누 만들기, 천연해충퇴치 스프레이와 천연버물리(시즌 체험) 등 직접 체험할 수 있는 다양한 프로그램을 제공하고 있다. 에코어드벤처는 숲속에서 나무와 나무사이를 와이어, 목재구조물, 로프 등으로 연결 하여 땅을 밟지 않고 나무와 나무사이를 이동하면

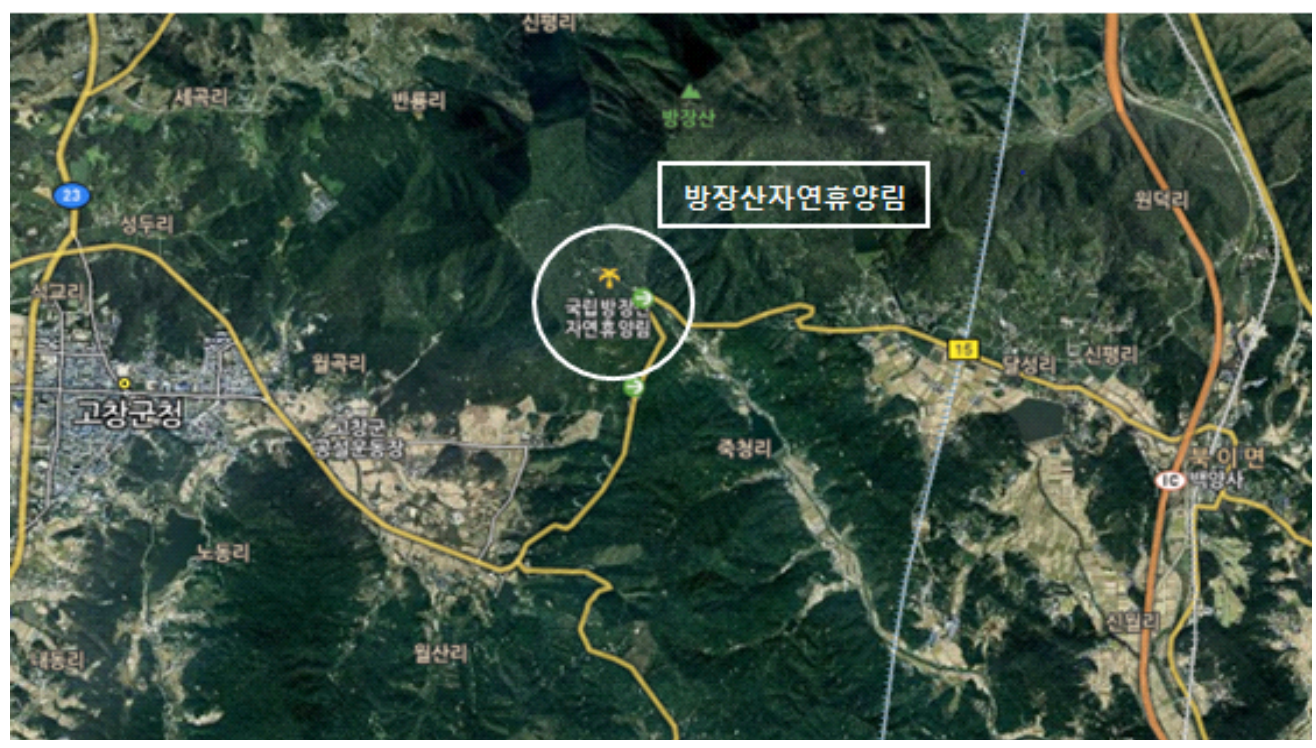

그림 1. 장성 방장산 자연휴양림 위치 
서 자연을 즐기는 친환경 레포츠 시설로 단체 20 명 이상을 사전 예약제로 운영되고 있다. 방장산자 연휴양림에 대한 관리인원(표 1), 운영실적(표 2), 숙박가동률은 표 3과 같다(안기완 등, 2016).

자연휴양림을 대상으로 이용행태 및 IP분석에 의한 활성화 방안을 제시한 연구 가운데, 임세윤 (2016)은 자연휴양림의 이용객이 증가하면서 요구 가 다양해지고 자연휴양림의 역할이 단순한 휴식을 제공하는 기능이 아닌 이용자의 특성에 따라 요구 사항과 만족을 고려해야 한다고 제안하였고, 이용 학 외(2016)는 국민들의 다양한 여가수요를 충족하 기 위해서는 자연휴양림의 공간 및 활동제공의 변 모가 필요하다고 지적한 연구결과들이 다수 있다. 그러나 광주광역시에서 가장 가깝게 위치하고 있는 방장산 자연휴양림에 대한 이용행태 및 활성화 연 구는 미흡한 실정이다.

이에 본 연구는 방장산 자연휴양림 방문객 대상 으로 이용행태 특성과 중요도-성취도 분석을 통해 방장산 자연휴양림이 안고 있는 문제점 및 발전방 안을 모색하고, 나아가 방장산 자연휴양림의 활성 화를 위한 정책수립의 기초자료를 제공하는데 목적
을 둔다.

\section{연구방법}

2017년 6월 15일 24일 간 방장산 자연휴양림을 대상으로 설문조사를 실시하였다. 구체적으로 방장 산 자연휴양림 숙박객과 1 일 방문객을 대상으로 무작위로 표본을 추출하여 사전에 훈련된 조사원과 방장산 자연휴양림 관리소 직원에 의해 조사를 실 시하였으며, 설문응답방식은 자기기입식방식과 일 대일면접을 병행하여 실시하였다. 설문지는 선행연 구들의 검토(임세윤, 2016; 김혜린, 2016; 문지연, 2016; 하경량, 2003)를 통하여 도출하였으며, 인지 도, 이용행태특성, 인구통계학적 특성, 중요도-성취 도 등 총 39 문항으로 구성하였다. 이용행태의 특성 의 측정을 위하여 방문횟수와 동반자 수는 비율척 도를, 나머지는 명목척도를 사용하였고, 중요도-성 취도 문항에 대한 측정은 5 점 리커트 척도를 사용 하여 연속자료가 되도록 구성하였다.

예비조사 차원에서 총 40 부에 대한 설문조사가 실시되었으며, 에디팅을 거쳐 내용이 부실하거나 사

표 1. 방장산 자연휴양림 관리직원 현황

단위: 명

\begin{tabular}{ccccccc}
\hline 합계 & 공무원 & 청원직 & 기간제(조리원) & 숲해설가 & 숲생태관리인 & 유아숲지도사 \\
\hline 12 & 1 & 2 & 3 & 5 & 2 & 1 \\
\hline
\end{tabular}

자료: 장성 방장산 자연휴양림 내부자료(2017년 12월말 현재)

표 2. 방장산 자연휴양림 이용실태

단위: 명, 백만원

\begin{tabular}{cccccccc}
\hline 연도 & 2010 & 2011 & 2012 & 2013 & 2014 & 2015 & 2016 \\
\hline 이용객 수 & 75,552 & 82,994 & 88,981 & 75,572 & 65,038 & 73,145 & 76,998 \\
수입 & 305 & 300 & 327 & 320 & 306 & 308 & 340 \\
\hline
\end{tabular}

자료: 장성 방장산 자연휴양림 내부자료

표 3. 방장산 자연휴양림 가동율 실태

단위: \%

\begin{tabular}{cccccccc}
\hline 연도 & 2010 & 2011 & 2012 & 2013 & 2014 & 2015 & 2016 \\
\hline 가동율 & 60 & 66 & 71 & 76 & 77 & 76 & 79 \\
\hline
\end{tabular}

자료: 장성 방장산 자연휴양림 내부자료 
용하기 곤란한 5 개 설문을 제외한 35 부를 분석하 여 자료로 사용하였다. 수집된 자료의 통계처리는 SPSS Statistics 23 프로그램을 활용하였으며, 분석 방법으로는 빈도분석, 다중응답분석, 신뢰도분석, 중 요도-성취도분석(IPA)을 사용하였다.

\section{결과 및 고찰}

\section{1. 방문객의 인구통계학적 특성}

방장산 자연휴양림의 이용행태 특성을 파악한 빈 도분석 결과는 표 4 와 같다. 방문객의 인구통계학 적 특성으로 성별 이용객은 비슷한 비율을 보였으 며, 연령은 40 대와 50 대 비율이 높은 편이었고, 학 력은 대졸 이상이, 월 가계소득은 500만 원 미만이 높은 비율을 차지하였으며, 이용그룹은 회사원 직 군이 높았고, 비교적 접근성이 양호한 광주광역시 이용객들이 높은 비율을 차지하였다. 위 결과는 경 기도 내 자연휴양림을 대상으로 연구한 임세윤(2016) 과, 강원도 내 자연휴양림을 대상으로 연구한 인광 선 외 2명(2014)의 연구결과와 거주지를 제외하고
비슷한 경향치를 보였다.

\section{2. 방문객의 이용행태 특성}

빈도분석 및 다중응답을 통해 파악한 방문객 이용 행태 특성 결과는 표 5 와 같다. 재 방문객 $(31.4 \%)$ 보 다 첫 방문객(68.6\%)의 비율이 2 배 가까이 차지하였 고, 동반유형은 가족단위 방문객이 주를 이루었다. 방 문객들은 주로 인터넷을 통하여 방장산 자연휴양림 에 대한 정보를 습득하고 있었으며, 이용목적은 휴양 을 위해 휴양림을 찾고 있었으며(46.5\%), 다음은 친 목도모 $(22.9 \%)$ 를 목적으로 하고 있었다. 이용시설은 숙박동과 체험프로그램을 진행하는 숲속공예마을과 등산코스를 이용하는 방문객이 많았다. 인구통계학적 특성과 마찬가지로 임세윤(2016), 인광선 외 2명 (2014)의 연구결과와 유사하며, 자연휴양림의 이용행 태는 주로 가족과 방문하며 인터넷으로 사전정보를 얻으며, 주로 휴양을 위해 방문한다는 결과를 얻었다.

\section{3. 중요도-성취도 분석}

IP 분석은 상품이나 서비스에 대한 이용자의 만

표 4. 인구통계학적 특성

\begin{tabular}{|c|c|c|c|c|c|}
\hline & 목 & 빈도(\%) & & 항목 & 빈도(\%) \\
\hline \multirow{2}{*}{ 성별 } & 남성 & $18(51.4)$ & \multirow{5}{*}{$\begin{array}{c}\text { 월평균 } \\
\text { 가계 } \\
\text { 소득 }\end{array}$} & 200 만 원 미만 & $2(5.7)$ \\
\hline & 여성 & $17(48.6)$ & & 300 만 원 미만 & $2(5.7)$ \\
\hline \multirow{4}{*}{ 연령 } & 30대 이하 & $6(17.1)$ & & 400만 원 미만 & $7(20.0)$ \\
\hline & 40대 & $15(42.9)$ & & 500만 원 미만 & $16(45.7)$ \\
\hline & 50대 & $9(25.7)$ & & 500 만 원 이상 & $8(22.9)$ \\
\hline & 60대 이상 & $5(14.3)$ & \multirow{9}{*}{ 거주지 } & 서울, 경기 & $3(8.6)$ \\
\hline \multirow{2}{*}{ 학력 } & 고졸 이하 & $7(20.0)$ & & 인천 & $1(2.9)$ \\
\hline & 대졸 이상 & $28(80.0)$ & & 대전 & $3(8.6)$ \\
\hline \multirow{6}{*}{ 직업 } & 자영업 & $3(8.6)$ & & 부산 & $2(5.7)$ \\
\hline & 공무원 & $3(8.6)$ & & 광주 & $14(40.0)$ \\
\hline & 전문직 & $2(5.7)$ & & 강원도 & $1(2.9)$ \\
\hline & 회사원 & $11(31.4)$ & & 충청도 & $1(2.9)$ \\
\hline & 전업주부 & $8(22.9)$ & & 전라도 & $8(22.9)$ \\
\hline & 기타 & $8(22.9)$ & & 경상도 & $1(2.9)$ \\
\hline
\end{tabular}


표 5. 방장산 자연휴양림 이용행태 특성

\begin{tabular}{|c|c|c|c|c|c|}
\hline \multicolumn{2}{|c|}{ 항목 } & \multirow{2}{*}{$\begin{array}{c}\text { 빈도(\%) } \\
24(68.6)\end{array}$} & \multicolumn{2}{|r|}{ 항목 } & \multirow{2}{*}{$\begin{array}{r}\text { 빈도(\%) } \\
1(2.9)\end{array}$} \\
\hline \multirow{2}{*}{$\begin{array}{l}\text { 방문 } \\
\text { 횟수 }\end{array}$} & 처음 & & \multirow{4}{*}{$\begin{array}{l}\text { 동반 } \\
\text { 유형 }\end{array}$} & 혼자 & \\
\hline & 재방문 & $11(31.4)$ & & 가족 & 29(82.9) \\
\hline \multirow{4}{*}{$\begin{array}{l}\text { 인지도 } \\
\text { 경로 }\end{array}$} & 신문/서적 & $1(2.9)$ & & 친구/연인 & $4(11.4)$ \\
\hline & 지인 & $8(22.9)$ & & 직장동료 & $1(2.9)$ \\
\hline & 인터넷 & $24(68.6)$ & \multirow{7}{*}{$\begin{array}{l}\text { 이용 } \\
\text { 시설 }\end{array}$} & 숲속공예마을 & $6(17.1)$ \\
\hline & 기타 & $2(5.7)$ & & 숙박동 & $14(40.0)$ \\
\hline \multirow{5}{*}{$\begin{array}{l}\text { 방문 } \\
\text { 동기 }\end{array}$} & 휴양 & $17(46.5)$ & & 솦속수련장 & $1(2.9)$ \\
\hline & 등산/산림욕 & $3(8.6)$ & & 등산코스 & $6(17.1)$ \\
\hline & 스트레스해소 & $3(8.6)$ & & 에코어드벤처 & $4(11.4)$ \\
\hline & 친목도모 & $8(22.9)$ & & 유아숲체험원 & $1(2.9)$ \\
\hline & 경치감상 & $4(11.4)$ & & 계곡 & $3(8.6)$ \\
\hline
\end{tabular}

족을 측정하기 위해 각 속성의 이용 전 중요도와 이용 후 만족도를 평가하여 각 속성의 상대적 중요 도와 성취도를 동시에 비교 분석하는 평가기법이 다. IP분석은 기대와 만족 평가를 동시에 함으로써 문제점을 명확히 제시하고, 결과해석이 용이하여 실무적인 활용도가 높다. I사분면은 중요도는 높으 나, 만족도가 낮아 집중관리가 필요한 영역이다. II 사분면은 중요도와 만족도가 높아, 지속적으로 잘 유지하는 전략이 필요하다. III사분면은 중요도와 만족도가 낮아, 관리의 우선순위를 낮추어도 무방 한 부분이며, IV사분면은 중요도는 낮으나 만족도 가 높아 불필요한 과잉 관리를 제거하거나 개선하 는 전략이 필요하다. IPA는 Martilla and James에 의해 소개된 이래 건강, 마케팅, 교육 등 여러 분 야에서 활용되었다(배국환, 2017).

본 연구는 방장산 자연휴양림의 활성화 방안을 제시하기 위해 IPA를 적용하였다. 방문객을 대상으 로 방장산 자연휴양림 이용 시 중요하다고 생각하 고 있는 중요도와 이용 후 성취도를 24 개 항목으 로 분류하여 조사한 후 평균값을 이용하여 IPA를 실시하였다. 설문 문항간의 내적일관성을 확보하기 위한 신뢰도분석 결과, Cronbach's $\alpha$ 계수는 0.880 으로 높게 나타났다.

그림 2에 나타난바와 같이 중요하다고 여기면서
동시에 만족도도 높은 제 1 사분면은 지속적으로 현재 상태를 유지시켜 주어야 한다. 제 1 사분면에 속하는 속성들로는 편의시설 위치 및 관리상태, 숙박동 관 리상태, 예약시스템, 시설이용료 등 총 10 개의 속 성이 해당하였다. 제 2 사분면은 방문객들이 중요하 다고 여기는 반면, 만족을 주지 못하는 항목들로 집 중적인 관리 및 운영을 필요로 하는 부분이다. 여 기에 속하는 항목들로는 화장실 위치 및 관리상태, 노약자/장애인 편의시설 배치, 주차장 위치 및 크기 총 3 개의 속성이 해당하였다. 방장산 자연휴양림은 경사가 심한 초입부에 화장실이 위치해 있고, 표시 판에 대한 관리가 제대로 이루어져 있지 않아 방문 객들은 화장실의 위치를 인지하기가 어려운 현실에 응답한 결과로 보이며, 화장실의 관리 상태에도 방 문객들에게 불편감을 주었던 요인인 것 같다. 제 3 사분면은 방문객들이 중요하다고 여기지도 않고 만 족을 주지도 못하는 속성으로 향후 많은 시간과 비 용을 투자하지 않아도 되는 속성들이 해당한다. 제 3 사분면에 해당하는 속성들로 프로그램 다양성, 프 로그램교육 효과, 프로그램 대상의 다양화 등 프로 그램에 해당하는 속성들이 많이 차지하였다. 제 4 사분면에 속한 항목들은 방문객들이 중요하다고 여 기지는 않지만 만족을 주고 있는 속성들로, 개선노 력을 다소 줄여야 하는 속성들이 속한다. 본 설문 


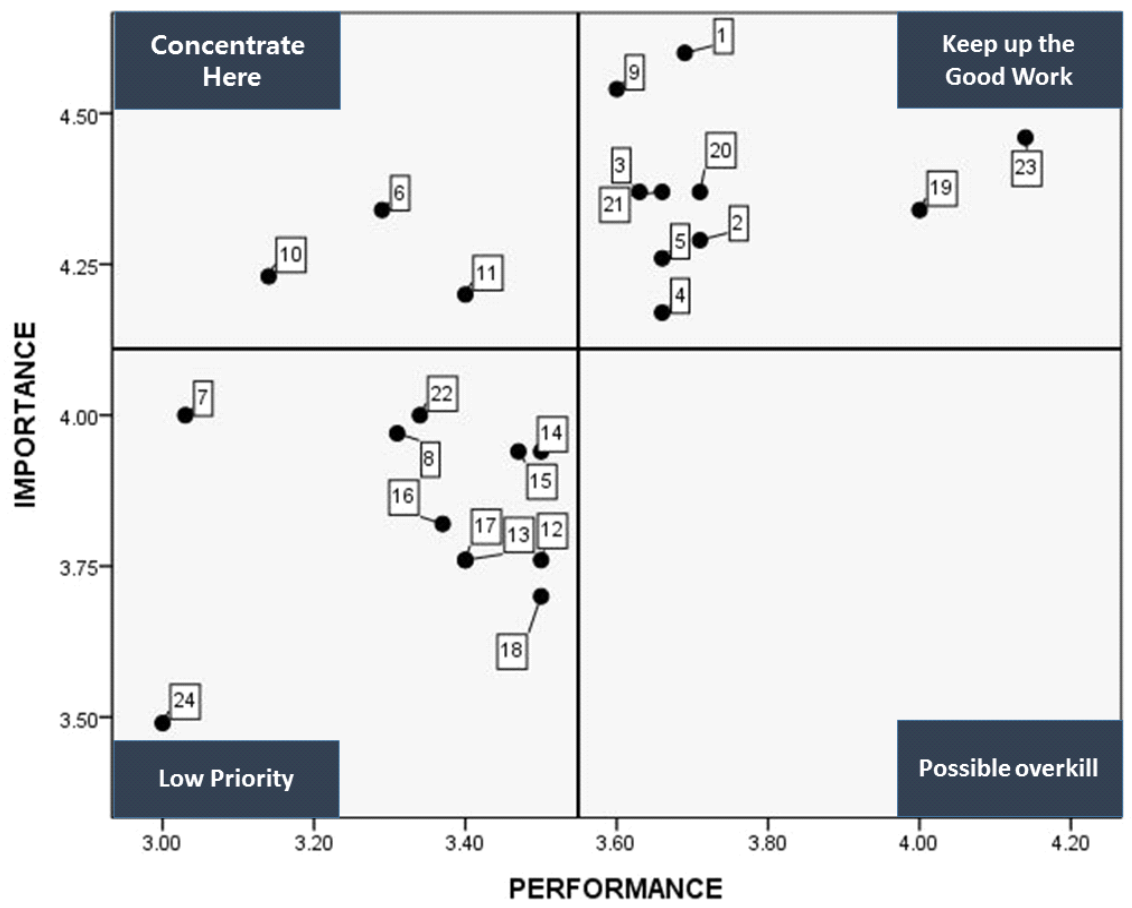

\begin{tabular}{|c|c|c|c|c|}
\hline & 편의시설 위치 및 관리상태 & 7 화장실 개수 & 13 체험 프로그램 다양성 & 19 안내서비스 및 원활한 정보제공 \\
\hline 2 & 산책/등산로 다양성 & 8 숙박동 개수 & 14 체험프로그램 흥미성 & 20 예약 시스템 \\
\hline 3 & 산책/등산로 주변 안전시설 & 9 숙박동 관리상태 & 15 야외 체험 프로그램 안정성 & 21 시설이용료 \\
\hline 4 & 산책/등산로 관리상태 & 10 노약자/장애인 편의시설 배치 & 16 체험 프로그램 대상의 다양화 & 22 숙박객 할인 서비스 \\
\hline 5 & 안내표지판 위치 및 관리상태 & 11 주차장 위치 및 크기 & 17 체험 프로그램 참가비 & 23 직원 친절도 \\
\hline 6 & 화장실 위치 및 관리상태 & 12 체험프로그램 제공 & 18 체험 프로그램 교육효과 & 24 주변마을연계 지역특산품 \\
\hline
\end{tabular}

그림 2. 방장산 자연휴양림 이용객의 IPA 결과

결과에서는 제 4 사분면에 해당하는 속성들이 없었 다. 이러한 본 연구결과는 임세윤(2016)의 시설환 경이 최우선이 되어야 할 요인으로 지적한 결과, 이용학 외(2016)의 자연휴양림과 주변체험마을의 적절한 연계가 이용객들에게 긍정적인 영향을 미칠 것이라 지적한 결과, 인광선 외(2014)의 시설서비 스와 위생상태 측면의 중요성 결과, 김범수(2011) 의 다양한 서비스 프로그램을 서비스 마케팅에 입 각하여 제공할 필요가 있다고 지적하고, 서비스 프 로그램이 방문율에 기여를 하고 있으니 프로그램의 전문적인 지도방법에 대한 연구와 프로그램에 대한 충실한 안내가 필요하다는 연구결과와 유사한 결과 가 도출되었다.

\section{결 론}

국립 자연휴양림은 국민들에게 산림에서의 다양
한 휴양, 교육 문화를 즐길 수 있는 자연 공간이 다. 최종적으로 국민들의 스트레스를 풀어주는 '녹 색쉼터'를 제공하는 것이 국립 자연휴양림의 최종 목표이다. 본 연구는 IPA 적용을 통해 방장산 자 연휴양림의 활성화 방안을 제안하고자 수행되었다. 그 결과를 요약하면 다음과 같다.

첫째, 방장산 자연휴양림 이용객 특성은 40 대와 50 대 비율이 높은 편이었고, 학력은 대졸이상, 월 가계소득은 500 만 원 미만, 회사원 직군, 비교적 접근성이 좋은 광주광역시에서 거주하는 이용객의 비율이 높게 나타났다. 둘째, 방문객의 이용행태의 특성은 첫 방문객(68.6\%)의 비율이 높았고, 가족단 위 방문객의 이용, 인터넷을 통해 정보를 습득하고 있었으며, 주로 휴양을 위한 방문비율이 높았다. 방문객들의 주 이용시설물은 숙박동과 솦속공예동, 등산코스로 나타났다. 셋째, 방문객들이 중요하다고 여기는 반면, 만족을 주지 못하는 제 2 사분면 항목 
은 화장실 위치 및 관리상태, 노약자/장애인 편의 시설 배치, 주차장 위치 및 크기의 속성으로 집중 적인 관리 및 운영이 요구되는 요인으로 나타났다.

자연휴양림에 대한 관심이 증가하고 있는 현실 에 방장산 자연휴양림에서 추구해야 할 적극적인 방안은 다음과 같다. 첫째, 2 사분면 속성에 해당하 는 IPA 결과에 대한 빠른 대응이 필요하다. 즉, 노 약자를 위한 등산로에 대한 안전시설 문제, 장애인 전용 객실의 추가 확보, 노약자 장애인 편의시설이 확충과 주차공간의 추가적인 확보, 자동차 야영장 구축에 대한 집중적인 검토가 필요하다. 둘째, 자 연휴양림에서 제공하는 서비스 프로그램은 방문율 에 기여를 하고 있다는 연구결과에 입각, 재방문율 제고에 대한 대응책이 추진되어야 할 것이다. 즉, 방장산 자연휴양림에 가장 인기가 높은 시설물인 숲속공예동에 대한 적극적 이용 및 교육시설인 솦 체원과 연계한 프로그램 개발, 프로그램에 대한 충 실하고도 적극적인 홍보, 다양한 프로그램을 서비 스 마케팅에 입각하여 제공할 필요가 있다고 본다. 또한 인근 체험마을과의 연계를 통한 마을프로그램 체험기회 또는 지역특산품 판매기회를 제공한다면 지역경제 활성화 및 주민 소득 증대에 기여할 것이 고, 방장산자연휴양림이 단순히 체류형 휴양지를 벗어나 순환형 휴양지로서 차별화가 될 것이며, 재 방문율 또한 높아질 것으로 기대된다.

본 연구는 방장산 자연휴양림의 문제점 도출을 통한 활성화 방안을 마련하고자 예비조사 차원에서 수행되었다. 따라서 설문의 표본이 적어 의견반영 에 한계점을 가지고 있으나, 향후 본 연구의 결과 를 바탕으로 구체적인 활성화 요인에 대한 연구를 수행하고자 한다.

\section{참고문헌}

1. 고수선, 한상열. 2017. 국립 자연휴양림의 이용객 수요에 따른 적정 조성개소수 예측 연구. 한국산림휴 양학회지. 21(2): 6, 73-81.

2. 국립자연휴양림관리소 : http://www.huyang.go.kr
3. 김혜린. 2016. 이용객 이용행태와 경제적 파급효과 분석에 의한 학술림 활성화 방안. 석사학위논문. 전남 대학교 일반대학원.

4. 김범수. 2011. 국유자연휴양림의 서비스 프로그램에 대한 IPA분석-산림환경교육과 산림문화프로그램을 대상으로- 한국환경과학학회지. 20(6): 721-728.

5. 문지연. 2016. 내장산국립공원의 시설물과 서비스에 대한 탐방객 만족도 분석. 석사학위논문. 전북대학교 대학원.

6. 박종찬. 2009. 방장산 자연휴양림 활성화 방안에 대 한 탐색적 연구: 방문행태와 만족도를 중심으로 호텔 관광연구. 11(4): 1-14.

7. 배국환, 공정민, 여기태. 2017. IPA 분석을 활용한 군 물류체계 개선방안에 대한 연구. 한국디지털정책 학회지. 15(3): 139-146.

8. 안기완, 김민희, 진승현. 2016. 캐나다 FireSmart 매뉴얼을 적용한 장성 방장산 자연휴양림 시설물의 산불 위험성 평가. 한국산림휴양학회지. 20(1): 3.

9. 윤혜진. 2006. 지역별 국유자연휴양림 활성화 방안에 관한 연구 -중요도-성취도(IPA) 기법을 중심으로Gho Hwang Non jib, Kyung Hee Graduate School. 39: 201-219.

10. 이용학 외 3인. 2016. 자연휴양림과 체험마을 연계를 위한 이용객의 선택속성 인식 연구. 한국조형학회지. 44(1): 16-28.

11. 인광선, 류동균, 주영환. 2014. 자연휴양림의 효율적 관리를 위한 IPA 적용강원도 내 자연휴양림을 중심 으로 한국산림휴양학회지. 18(1): 71-84.

12. 임세윤. 2016. 자연휴양림의 중요도, 만족도 및 재방 문 의도: 경기도 자연휴양림을 중심으로. 석사학위 논문. 서울시립대학교 도시과학대학원.

13. 하경량. 2003. 자연휴양림의 입지 특성과 이용객의 행태분석: 전남을 시례로 박사학위논문. 전남대학교 일반대학원.

14. Martilla, J. A. and James, J. C. 1977. Importance-performance analysis. The Journal of Marketing. 41(1): 77-79. 